\title{
Vida de Maria, de Epifânio o Monge: contribuição de uma obra da patrística oriental para a mariologia
}

\author{
Life of Mary, of Epiphanius the Monk: \\ contribution of a work of Eastern Patristic to Mariology
}

Afonso Tadeu Murad

\section{Resumo}

"Vida de Maria" é uma obra da patrística oriental a respeito da Mãe de Jesus, escrita pelo Monge Epifânio, no final do século VIII. Ela conjuga elementos da piedade popular e da literatura edificante da Igreja bizantina. $\mathrm{O}$ autor reúne os dados que dispõe e organiza a obra em 26 pequenos capítulos, não repetindo o conteúdo dos evangelhos canônicos. Usa de forma equilibrada e crítica os elementos das narrativas apócrifas, sobretudo a respeito da concepção virginal, da opção celibatária e da "dormição" da Mãe de Jesus. Epifânio apresenta as seguintes características do perfil de Maria: mãe virginal do messias, mulher proativa, seguidora de Jesus, companheira de outras mulheres na comunidade cristã, modelo das consagradas e dos consagrados, santa glorificada por Jesus (dormição). Assim, a obra é inspiradora para a mariologia contemporânea, pois situa Maria no mistério de Jesus Cristo e da Igreja de seu tempo. Esse artigo visa: tornar conhecida "A vida de Maria"; apontar elementos significativos desta obra para a teologia e a devoção marianas; mostrar a influência dos apócrifos para uma visão mágica de Maria, distante do seu perfil bíblico; refletir sobre o discernimento na escolha das fontes da mariologia; e suscitar novas pesquisas.

Palavras-chave: Mariologia. Vida de Maria. Epifânio Monge. Dormição. 


\begin{abstract}
"Life of Mary" is a work of the Eastern patristic concerning the Mother of Jesus, written by the Monk Epiphanes, in the late eighth century. It combines elements of popular piety and the edifying literature of the Byzantine Church. The author gathers the data he has and organizes the work into 26 small chapters, not repeating the content of the canonical gospels. He uses in a balanced and critical way the elements of apocryphal narratives, especially regarding the virginal conception, the celibate option and the "dormition" of the Mother of Jesus. Epiphanius presents the following characteristics of Mary's profile: virgin mother of the messiah, proactive woman, follower of Jesus, companion of other women in the Christian community, model of consecrated and consecrated women, saint glorified by Jesus (dormant). Thus, the work is inspiring for contemporary mariology, because it places Mary in the mystery of Jesus Christ and the Church of her time. This article aims to: make known "The life of Mary"; to point out significant elements of this work for Marian theology and devotion; show the influence of the Apocrypha to a magical vision of Mary, far from her biblical profile; reflect on the discernment in the choice of sources of mariology; and raise new research.
\end{abstract}

Keywords: Mariology. Life of Mary. Epiphanius Monk. Dormition.

\title{
Introdução
}

"Vida de Maria" do monge oriental Epifânio" é considerada uma das mais antigas narrativas sobre Maria que abarca todo o percurso da existência da Mãe de Jesus, da concepção até a glorificação. Escrita provavelmente no final do século VIII, não consiste em uma biografia, no sentido contemporâneo do termo. Nem em texto apócrifo, pois o autor é conhecido e não recorre a autoridade de outro para ser aceito. Trata-se sim, de uma narração que mescla elementos "da piedade popular e da literatura edificante do oriente", no final do

\footnotetext{
${ }^{1}$ Não deve ser confundido Santo Epifânio, bispo de Salamina (+ 403), que também escreveu sobre Maria, três séculos antes. Veja o fragmento do seu clássico texto "Os últimos dias da Virgem Maria".
} 
período patrístico. Transparecem traços da espiritualidade da Igreja bizantina, em luta contra a iconoclastia, e o impulso místico que a conduz. ${ }^{2}$

Ao final da Idade patrística, a devoção mariana havia se desenvolvido bastante, sobretudo no Oriente. Foi registrada sobretudo em ícones, em hinos e em homilias, como as de Germano de Constantinopla, André de Creta e João Damasceno. ${ }^{3}$ Desde o século III até essa época circulavam relatos e textos apócrifos sobre Maria, referentes ao seu nascimento, infância, concepção, nascimento e educação de Jesus, bem como a glorificação da Theotókos, denominada no oriente como "dormição".

Neste contexto, surge a obra de Epifânio de Constantinopla, monge e presbítero bizantino. Ao que consta, Epifânio viveu entre o final do século VIII e início do século IX. Provavelmente, morou por muitos anos no monastério de Calistratos, em Constantinopla. ${ }^{4}$ Fez várias viagens, percorrendo a Ásia menor. Os poucos detalhes biográficos sobre Epifânio se encontram em outro escrito de sua autoria, "a Vida de Santo André". Sua dupla condição de presbítero e monge não era comum na região. A crise produzida pela iconoclastia levou, em contrapartida, a uma revalorização da vida dos santos e das representações iconográficas, especialmente da Theotókos. ${ }^{5}$ Neste sentido, a narração e a representação pictográfica se completam.

Epifânio pretende ordenar cronologicamente os acontecimentos sobre a Mãe de Jesus e purificar aquilo que lhe parece contrário à reta fé cristã. Sua breve narrativa denomina-se "Tratado sobre a Vida e os anos da Santíssima Mãe de Deus" ou "A vida da Theotókos". Encontra-se no compêndio da patrística grega. ${ }^{6}$ Ignorado em várias obras que reúnem contribuições dos Padre da Igreja para a mariologia, a "Vida da Theotókos", encontra-se no tomo 2 (Padri e altri autori bizantini) da volumosa compilação "Testi mariani del Primo Millenio". Intitula-se: "Discorsi sulla vita della Santissima Madre de Dio". 7 A versão em espanhol, "Vida de María", que utilizamos aqui com as citações literais, contém: introdução, tradução e notas de Guillermo PONS PONS (1996). Ambas as traduções reportam ao códice da Biblioteca Naniana, transcrito em latim por Mingarelli (+1793).

\footnotetext{
${ }^{2}$ EPIFANIO, Introdução, p. 5.

${ }^{3}$ DAMASCENO, Homilias cristológicas y marianas, p. 117-213.

${ }^{4}$ EPIFANIO, Introdução, p. 10.

${ }^{5}$ EPIFANIO, Introdução, p. 12.

${ }^{6}$ PG $120,185-216$.

${ }^{7}$ GHARIB, G. et al (Orgs.), Testi mariani del Primo Millenio, p. 783-799.
} 
Neste artigo, nos propomos a: (a) apresentar uma síntese acessível deste texto da patrística oriental, de forma a torná-lo conhecido para o grande público; (b) apontar elementos significativos desta obra para a teologia e a devoção mariana; (c) mostrar a influência dos apócrifos, que corroboraram para uma visão mágica de Maria, distante do seu perfil bíblico; (d) refletir sobre o discernimento na escolha das fontes da mariologia; (e) suscitar novas pesquisas.

Não se pretende empreender um minucioso estudo de teologia patrística, tarefa apropriada para um especialista da área. Nem tampouco uma pesquisa histórico-crítica, para identificar quais elementos da narração remontam historicamente a Maria de Nazaré. Trata-se simplesmente de um ensaio de teologia pastoral mariana, à luz deste belo texto narrativo patrístico. $\mathrm{O}$ foco reside na questão: como este texto, mesmo sem o rigor da historiografia contemporânea, contribui para uma compreensão equilibrada sobre a mãe de Jesus e evita os exageros dos apócrifos?

\section{Visão panorâmica da "Vida de Maria"}

Epifânio pretende relatar somente os fatos que considera como verdadeiros. ${ }^{8}$ Apoia-se, com reservas, em apócrifos como o Protoevangelho de Tiago. Também incorpora elementos do apócrifo assuncionista "Livro de São João Evangelista (o teólogo)". Critica outros manuscritos que circulavam no seu tempo. Confia demasiadamente nos escritos do Pseudo Dionísio, que ele considerava como o verdadeiro Dionísio, discípulo de Paulo. Serve-se de informações de várias fontes, sem conferir a elas total crédito. Tal prudência leva-o a usar termos como "dizem que" ou "alguns dizem...". Na introdução, Epifânio justifica a originalidade de seu trabalho:

Dentre os Santos Padres, houve quem celebrasse Maria com grandes louvores. Mas nenhum deles escreveu com exatidão a respeito de sua vida, de sua educação e do seu trânsito (...) André de Jerusalém, que foi bispo de Creta, escreveu brevemente sobre este assunto. Porém, ele fez mais um elogio do que uma narração. ${ }^{9}$

\footnotetext{
${ }^{8}$ VM 1. Sempre que fizermos referência à "Vida de Maria" de Epifânio, usaremos a sigla "VM", com os respectivos capítulos (e não as páginas).

${ }^{9} \mathrm{VM} 1$.
} 
Nosso monge quer apresentar uma biografia piedosa e bem fundamentada sobre Maria, de forma a acentuar que ela é um exemplo de vida para os cristãos, especialmente os que abraçam a vida monástica. Mas não se pode esperar que sua narrativa tenha a objetividade buscada pela historiografia moderna. Assim diz ele:

Após termos examinado com atenção muitos escritos, apresentamos aos leitores interessados, em estilo simples, aquilo que se refere a Maria. Sempre que sejam dignas de crédito, sólidas e verdadeiras; recolhendo-as tanto da História de Eusébio (..) como de outros escritores e mestres. E para que ninguém nos acuse de termos suprimido ou aumentado algo, colocamos a citação de cada autor em quem nos apoiamos..$^{10}$

O relato está dividido em 26 pequenos capítulos, com o seguinte conteúdo:

1. Introdução. Credibilidade das fontes utilizada

2. Maria e José, primos segundo a lei

3. Concepção e nascimento de Maria

4. Maria é consagrada no templo de Jerusalém

5. Qualidades da jovem Maria

6. Perfil de Maria, modelo de virgem consagrada

7. Primeiro casamento e viuvez de José. Menarca de Maria

8. Maria é entregue a José, como guardião de sua virgindade

9. Anúncio a Maria e a Zacarias

10. Desejo sexual e virgindade no parto

11. Visita a Isabel e volta à casa de José

12. Nascimento de Jesus. Vinda dos magos. Apresentação no templo

13. Matança das crianças. João no deserto

14. Retorno do Egito. Os irmãos de Jesus

15. Aparência de Jesus

16. Missão de João Batista

17. Início da missão de Jesus

18. Seguidores e seguidoras de Jesus

19. Maria Madalena e os doze apóstolos

20. Santa Ceia, cruz e ressurreição

${ }^{10} \mathrm{VM} 1$. 
21. Manifestações do ressuscitado. Maria, outras mulheres e os apóstolos 22. Maria na comunidade primitiva

23. Alguns presentes na dormição de Maria

24. Paulo e as almas dos justos também estavam lá

25. O trânsito de Maria

26. Conclusão: períodos da vida de Maria

O autor compõe a narração com um recurso literário típico de novelas, de tal forma que os vários personagens são colocados como parentes próximos ou conhecidos. Por exemplo, Maria e José seriam primos segundo a lei do levirato; filhos de dois irmãos, respectivamente Joaquim e Eli. Já Cléofas (ou Clopas), seria irmão uterino de José, da parte de Jacob. ${ }^{11}$ A tia de Maria de Nazaré, irmã de Ana, também chamada de Maria, teria como filha a Salomé, que foi a parteira da Virgem de Nazaré. ${ }^{12}$ Mais. Ageu, irmão de Zacarias e tio de João Batista, é considerado como o pai de Salomé, mulher do primeiro matrimônio de José, o carpinteiro. Que novelo familiar, com tantos fios de parentesco!

Epifânio é sóbrio quando discorre sobre os pais de Maria, Joaquim e Ana. Evita a visão triunfalista dos apócrifos do nascimento da Virgem de Nazaré. Diz somente que os dois viviam juntos há 50 anos, sem terem descendência. Joaquim, ao orar no templo, recebe uma revelação de que terá um(a) filho(a). Então, "Ana concebeu na velhice e deu à luz uma filha e lhe colocaram o nome de Maria, por causa de sua irmã. Todos os seus familiares e amigos se alegraram com ela". ${ }^{13}$

Vejamos agora a relação da "Vida de Maria" com os apócrifos. E a seguir, algumas particularidades desse belo texto, e sua atualidade para a devoção e a teologia marianas.

\section{Epifânio e os apócrifos marianos}

Não sabemos, com precisão, quais elementos Epifânio toma dos apócrifos marianos conhecidos nas comunidades cristãs do oriente. Embora nesta época o cânon das escrituras estivesse definido, alguns escritos gozavam de grande

\footnotetext{
${ }^{11}$ VM 2.

${ }^{12} \mathrm{VM} 3$.

${ }^{13} \mathrm{VM} 3$.
} 
reputação. Vejamos os principais apócrifos, orientais e ocidentais, que contêm referências a Maria. ${ }^{14}$

(a) Evangelho do Pseudo-Mateus: datado provavelmente do século IV, conta sobre o nascimento de Maria e a infância de Jesus, com elementos gnósticos. Narra fatos exagerados e mágicos, sem qualquer fundo histórico. Por exemplo: Maria habita no templo de Jerusalém a partir dos três anos de idade. Lá se destaca como uma "supermulher", mostrando-se em tudo melhor que as outras. O Menino Jesus, por sua vez, realiza vários milagres. Ele não aceita nenhum professor que José lhe recomenda, pois afirma orgulhosamente ser ele mesmo $\mathrm{O}$ mestre.

(b) Evangelho da Natividade de Maria: do século II, narra como foi importante o papel de Maria na história de Jesus. Sob forte influência gnóstica, está repleto de elementos mágicos, como o nascimento de Jesus sem parto real. Conforme alguns pesquisadores, seria o apócrifo mariano mais antigo, na versão do papiro Bodmer, e estaria na base do Protoevangelho de Tiago.

(c) Protoevangelho de Tiago (PET): originado provavelmente no século III, é atribuído a Tiago, o irmão do Senhor. Apresenta o nascimento de Maria como um fato extraordinário. Ela é filha de um casal estéril, Joaquim e Ana. Descreve a consagração de Maria no templo, o casamento com o ancião José (viúvo com seis filhos) e a virgindade no parto. Acrescenta fatos narrados por Mateus, como a anunciação a José. Esse texto apócrifo influenciou a devoção popular (como as festas de Santana e da consagração de Maria). Também forneceu elementos para a iconografia cristã. Por exemplo, José seria um senhor idoso, de barbas brancas.

(d) História de José, o carpinteiro: remonta ao século IV ou V, do Egito. Os manuscritos que restaram são posteriores, provavelmente do século IX. Narra-se a história de José, contada por Jesus aos apóstolos no monte das Oliveiras. E, naturalmente, Maria aparece em vários momentos: a vida no templo, o casamento com José, o nascimento em Belém, a fuga para o Egito e a aflição diante da morte de José.

(e) Evangelho armênio da Infância: reflete sobre a relação de Maria com o Menino Jesus. Afirma que ela concebeu do Espírito Santo pelo ouvido, já que o Cristo é a Palavra! ${ }^{15}$ Maria é colocada como a nova Eva e mãe da

\footnotetext{
${ }^{14}$ A lista que se segue provém de MURAD, A., Maria, toda de Deus e tão humana, p. 48-51. As datas de origem dos apócrifos não são precisas. Depende da opção do compilador e de suas fontes. Basta comparar os dados apresentados pelo clássico livro de SANTOS OTERO, A. (Ed.)., Los Evangelios Apócrifos, p. 415; MORALDI, L., Evangelhos apócrifos, p. 393.

${ }^{15}$ Evangelho Armênio V, 9.
} 
humanidade. ${ }^{16}$ Ali se nomeiam os Reis Magos, como Melquior, Gaspar e Balthasar. ${ }^{17}$ Originalmente, escrito no século VI.

(f) Trânsito de Maria do Pseudo-Melitão de Sardes: narra a morte, o enterro, e a glorificação de Maria. Possivelmente originário do século IV, embora os melhores manuscritos datem do século VIII.

(g) Livro de São João Evangelista, o teólogo, sobre a passagem da Santa Mãe de Deus: originado entre os séculos IV a VI, este texto conta os detalhes da morte de Maria e sua ida para o céu num domingo.

(h) Livro de São João, arcebispo de Tessalônica: organizado em forma de homilia, o texto discorre sobre a morte e a dormição de Maria. Datado provavelmente no século VI, teve grande influência na devoção mariana posterior.

As pesquisas arqueológicas e documentais atestam que grande parte das narrações apócrifas não tem fundamento histórico. Foram criadas por seus autores, visando transmitir uma mensagem religiosa. É inconcebível a euforia dos pais de Maria por ocasião do nascimento da menina, narrada pelo Protoevangelho de Tiago, ${ }^{18}$ pois na cultura judaica se desejava o primogênito homem. Quando nascia uma menina, era motivo de tristeza para a família! Da mesma forma, não se pode afirmar que Maria viveu no Templo de Jerusalém como virgem consagrada, desde os três ou os oito até os doze anos de idade, ${ }^{19}$ como sustentam vários apócrifos, pois não havia tal costume no tempo de Jesus. Sem contar elementos mitológicos, como a presença de Eva no nascimento de Jesus. ${ }^{20}$

Mais grave é a questão teológica. Vários apócrifos sustentam uma visão equivocada de Jesus, negando sua natureza humana e o realismo da encarnação. E tal percepção se estende a Maria. A narração do parto virginal de Jesus, no Evangelho da infância de Maria, está carregada de elementos mágicos, rejeitando que o Filho de Deus "se fez carne e veio morar entre nós" (Jo 1,14)! Há inúmeras cenas mirabolantes, que não condizem com o perfil de Cristo. O Evangelho do Pseudo Tomé (EPT) ${ }^{21}$ narra que aos cinco anos de idade o menino Jesus modelou doze passarinhos com barro, num sábado. Foi

\footnotetext{
${ }^{16}$ Evangelho Armênio IX,1-3.

${ }^{17}$ Evangelho Armênio V,10.

${ }^{18}$ PET III - IV.

${ }^{19}$ PET VII.

${ }^{20}$ Evangelho Armênio IX,1-3.

${ }^{21}$ RAMOS, L. (Ed.)., São José e o Menino Jesus.
} 
então denunciado a José por um judeu. Quando José o repreendeu, Jesus bateu as mãos, voltou-se para os passarinhos de barro e disse-lhe: "ide". Então, abrindo as asas, esses voaram, gorjeando. ${ }^{22}$ Pior ainda é o caso do menino que, correndo, esbarrou em Jesus pelas costas. Irritado, Jesus the disse: "não continuarás o teu caminho". E a criança caiu morta. ${ }^{23}$

$\mathrm{Na}$ introdução de sua obra, Epifânio assume que tomou elementos dos apócrifos. Mas também faz questão de denunciar os equívocos de alguns deles.

Os que realizaram tal intento (de escrever uma Vida de Maria), e em parte tocaram o tema, se distanciaram do reto caminho e acabaram por se contradizer a si mesmos. Por exemplo: Jacob, o hebreu, ${ }^{24}$ Afrodisiano, o persa. E alguns outros, que somente abordaram o nascimento de Maria, com certa restrição, e guardaram silêncio. João o tessalonicense, que escreveu uma dissertação sobre a Dormição, terminou obscuro. Outro João, que se denomina o "teólogo", demonstra-se cheio de mentira ${ }^{25}(. .$.$) .$ Que ninguém nos reprove por aquilo que aceitamos dos apócrifos e dos hereges. Pois os testemunhos dos adversários são mais dignos de crédito, como afirma São Basílio Magno. ${ }^{26}$

Vejamos agora os principais elementos teológico-pastorais da "Vida de Maria" para a reflexão mariana atual.

\section{Maria em relação a Cristo, aos discípulos e às discípulas}

Escrito entre os séculos VIII e IX, a "Vida de Maria" se diferencia em vários aspectos das narrações apócrifas, mesmo as mais antigas. Com algumas exceções, o autor não mistura sua versão com os textos bíblicos. Esse recurso, comum no "Protoevangelho de Tiago" e no "Pseudo Mateus", por exemplo, induz o leitor a acreditar que se trata de um texto digno de fé. Tal procedimento leva à confusão. Epifânio alude aos textos bíblicos, mas não os

\footnotetext{
${ }^{22}$ EPT III, 1-4.

${ }^{23}$ EPT IV, 1.

${ }^{24}$ Segundo PONS, nota 7, Epifânio refere-se aqui ao Protoevangelho de Tiago. Ele provavelmente não teve acesso aos apócrifos ocidentais, como o Evangelho do Pseudo Mateus ou o Evangelho da Natividade de Maria (EPIFANIO, Vida de María, p. 23-24).

${ }^{25}$ O apócrifo "Tratado de São João, o teólogo, sobre a Dormição da Mãe de Deus” foi muito difundido no oriente bizantino.

${ }^{26} \mathrm{VM} 1$.
} 
insere na sua narrativa. Talvez pelo respeito à Palavra de Deus, proclamada na oração comunitária e na liturgia. Fornece apenas chaves de leitura, conforme a tradição que ele herdou.

No livrinho de Epifânio há alguns capítulos cristológicos, que sintetizam e interpretam dados dos Evangelhos, como: o anúncio de João Batista, ${ }^{27}$ o começo da missão de Jesus, ${ }^{28}$ a celebração da ceia, a morte de cruz e a ressurreição. ${ }^{29}$ Esse procedimento fornece uma chave hermenêutica imprescindível para a atualidade: narrar a vida de Maria de Nazaré à luz da vida e da missão de Jesus Cristo.

Epifânio destaca a participação de várias mulheres na vida de Maria, constituindo uma corrente de solidariedade e "sororidade". Seguindo a tradição apócrifa narra que "quando a menina completou sete anos, novamente os pais a levaram a Jerusalém e a ofereceram ao Senhor, consagrada para todos os dias da sua vida". ${ }^{30}$ E acrescenta outras coisas. Segundo Epifânio, seu pai Joaquim logo morreu. Então, “Ana deixou Nazaré e foi morar em Jerusalém, permanecendo próxima de sua filha Maria". ${ }^{31}$ Mas faleceu dois anos depois. Maria ficou órfã, sem proteção ao seu redor, e habitava no Templo do Senhor. Nessa situação tão delicada, diz nosso autor, quando Maria precisava de algo, acudia a Isabel, que morava ali perto. ${ }^{32}$

Maria é ajudada por outras mulheres também por ocasião do nascimento de Jesus: "e naquela noite a Santa Virgem deu à luz ao Emanuel. A parteira Salomé cuidava de tudo (...) Havia ali uma gruta, estábulo de animais. Sabendo Isabel da sua presença, levou-lhes tudo o que necessitavam. E o mesmo fizeram outros parentes". ${ }^{33}$

$\mathrm{Na}$ narrativa de Epifânio, Maria faz parte efetivamente dos seguidores de Jesus, desde a Galileia. Assim, no começo da vida pública, “(..) veio Jesus a Zebeda, com sua Mãe e seus discípulos, e se hospedaram em casa de Zebedeu, que tinha sua mulher e dois filhos, Tiago e João. E os tomou como discípulos". ${ }^{34}$

\footnotetext{
${ }^{27} \mathrm{VM} 16$.

${ }^{28} \mathrm{VM} 17$.

${ }^{29} \mathrm{VM} 20$.

${ }^{30} \mathrm{VM} 4$.

${ }^{31} \mathrm{VM} 4$.

${ }^{32} \mathrm{VM} 5$.

${ }^{33} \mathrm{VM} 6$.

${ }^{34} \mathrm{VM} 18$.
} 
Epifânio conta que, por ocasião da morte de Zebedeu, Tiago e João "foram lá e enterraram o pai. Mas levaram sua mãe a Cristo. E essa conviveu com a Theotókos pelo resto da sua vida". ${ }^{35}$ Fundindo dois relatos diferentes do Evangelho de Lucas, narra que "Salomé, a esposa de Cusa, administrador de Herodes de Filipos, a qual tinha sete maus espíritos, tendo se aproximado e suplicado a Cristo, foi libertada dos espíritos e já não se afastou do Senhor, mas o seguia". ${ }^{36}$

Entre essas mulheres, destaca-se a figura de Maria Madalena, que está colocada no mesmo capítulo onde são apresentados os doze apóstolos. ${ }^{37}$ Ele identifica Maria, irmã de Lázaro, com Madalena. E diz:

\begin{abstract}
Então, voltou à Galiléia e chegou à cidade de Mágdala. Uma mulher chamada Maria the deu hospedagem em sua casa. Tendo ouvido suas palavras e visto os milagres que fazia, renunciou a todos os seus bens, e aderindo a Cristo, seguiu-o. Ela convivia com a Theotókos e outras mulheres. Era muito prudente e fervorosa no espírito e nas lágrimas, igual a Pedro, e servia-lhes com seus bens. ${ }^{38}$
\end{abstract}

Maria e as mulheres fazem parte do grupo efetivo dos seguidores de Jesus, não somente na Galileia. "Jesus veio para a Judéia com sua mãe e seus numerosos discípulos. Esses, anunciando o Evangelho por todos os lugares, batizando e curando, subiram a Jerusalém". ${ }^{39}$ E a Maria se juntam ainda outras mulheres. "Todos juntos iam pelos povoados e pelos campos, pregando o Reino e curando todas as doenças e enfermidades. A sogra de Pedro, que tinha sido curada, juntamente com sua filha, a esposa de Pedro, seguiu-os, e convivia com a Theotókos". ${ }^{40}$

De forma original, Epifânio afirma que homens e mulheres participaram da última ceia: "lá prepararam a Páscoa, isto é, a ceia mística, para Cristo com

\footnotetext{
${ }^{35} \mathrm{VM} 18$.

${ }^{36} \mathrm{VM} 18$.

${ }^{37}$ Aqui se encontra uma pista para futuras pesquisas. Epifânio reconhece o lugar singular de Maria Madalena na comunidade dos discípulos e discípulas de Jesus. Neste sentido, converge com a visão do apócrifo "O Evangelho de Maria" (Madalena). Mas não há traços da visão gnóstica na obra do nosso monge (FREITAS FARIA, J., O outro Pedro e a outra Madalena segundo os apócrifos, p. 135-153).

${ }^{38} \mathrm{VM} 19$.

${ }^{39} \mathrm{VM} 18$.

${ }^{40} \mathrm{VM} 17$.
} 
seus discípulos e discípulas". ${ }^{41}$ Portanto, no relato de Epifânio, Maria e outras mulheres estão sempre na presença de Jesus. São de fato discípulas dele.

Segundo a tradição oriental, a partir do relato de Marcos e João, elogiamse as três mulheres que foram ao sepulcro ungir Jesus. Elas são chamadas de miróforas (literalmente: as que levam o óleo perfumado para a unção). Joana, Maria e Salomé são celebradas na Igreja bizantina no terceiro domingo da Páscoa, com orações e cantos próprios. ${ }^{42}$ Também a Igreja luterana comemora as miróforas. ${ }^{43}$

Epifânio faz um arranjo, e amplia consideravelmente a lista, de três para sete miróforas, destacando as relações parentais: (1) Maria Madalena; (2) Salomé, mãe dos filhos de Zebedeu; (3) Maria, a mãe de Tiago; (4) a mulher de Judas, irmão do Senhor; (5) a mãe de José, a que tinha educado ao irmão do Senhor; (6) Joana, que seria a esposa de Pedro ou a mãe de Clemente; e (7) Maria de Cleófas, que seria irmã de Maria e mulher do irmão de José. Estas miróforas foram sete vezes, pela noite, ao túmulo do Senhor e não viram quando ele ressuscitou. ${ }^{44}$

Nosso monge inclui Maria, as mulheres e os irmãos de Jesus no rol daqueles que, várias vezes, presenciaram o Cristo ressuscitado e então partiam em missão, desde o Cenáculo, que ele denomina "Santa Sião". O evangelista João, chamado "o teólogo", teria comprado este imóvel para a comunidade, com o dinheiro da herança de seu pai Zebedeu. ${ }^{45}$

Lá se encontravam todos com Ela (Maria). Todos os apóstolos com as mulheres e com os irmãos do Senhor, jejuando, prostrados no chão, chorando, rezando e cantando hinos constantemente, com grande devoção. Lá Cristo aparecia-lhes frequentemente. Indo como enviados, a diversos lugares, de novo lá se congregavam. ${ }^{46}$

Segundo Epifânio, após a morte de Estevão e a ascensão do Senhor, os discípulos se dispersaram, com exceção dos doze. Eles permaneceram na casa

\footnotetext{
${ }^{41} \mathrm{VM} 20$.

${ }^{42}$ DOMINGO das santas miróforas.

${ }^{43}$ No dia 03 de agosto a Igreja Luterana faz a memória de Joana, Maria e Salomé, as portadoras de mirra (miróforas), também conhecidas como "as mulheres fiéis". A esse respeito, ver: AS SANTAS Mirófiras de Jesus. Teologia Luterana.

${ }^{44} \mathrm{VM} 21$.

${ }^{45} \mathrm{VM} 18$.

${ }^{46} \mathrm{VM} 21$.
} 
de João (a santa Sião), junto com Maria e algumas mulheres, vindas de várias localidades. Dentre elas, talvez estivesse até a mulher do apóstolo Paulo(!). ${ }^{47}$ Ali teriam morado por vinte e quatro anos, até a dormição da Theotókos ${ }^{48}$

Então, de maneira admirável, Epifânio narra a vida de Maria em estreita relação com a pessoa e a missão de Jesus: concepção, nascimento, vida pública, morte, ressurreição e ascensão. De forma inequívoca, associa Maria, várias mulheres, os dozes apóstolos, e os irmãos de Jesus à ação salvadora do Filho de Deus encarnado.

No conjunto da narrativa, ele enxerta elementos devocionais como a virgindade perpétua de Maria e sua glorificação, pelo Filho ressuscitado. Além disso, traça um perfil idealizado da figura de Maria, como modelo de vida monástica para homens e mulheres.

\section{Maria, modelo dos consagrados e consagradas na vida monástica}

Epifânio segue a tradição que recebeu, segundo a qual Maria foi levada ao templo aos 7 anos e ali viveu, como virgem consagrada até o início da adolescência. Anos depois, para não manchar o templo com sangue, devido à inevitável vinda da menstruação, Maria é entregue pelos sacerdotes do templo a José, um velho viúvo. A primeira narrativa que conhecemos sobre este tema remonta ao Papiro Bodmer, Evangelho da Natividade de Maria ${ }^{49} \mathrm{O}$ texto sofreu uma ampliação com mais elementos mágicos no Protoevangelho de Tiago. Vários componentes foram assumidos por grandes figuras da patrística, como se fossem factuais.

A novidade de Epifânio consiste em apresentar Maria como o modelo dos consagrados. Não somente das mulheres virgens, mas também dos homens. Assim ele apresenta o perfil humano-espiritual da adolescente Maria, consagrada no templo:

Maria aprendeu as letras hebraicas com seu pai Joaquim, quando este ainda vivia. Era inteligente e com desejo de aprender. Embora fosse órfã, dedicava-se ao estudo das divinas letras. Era admirada pelos seus trabalhos de tecelagem de lã e linho, de seda e de algodão. Pela

\footnotetext{
${ }^{47} \mathrm{VM} 22$.

${ }^{48}$ VM 26.

${ }^{49}$ Dentre as traduções disponíveis, sugerimos: RAMOS, L. (Ed.)., A história do nascimento de Maria, p. 67.
} 
sua sabedoria e inteligência diferenciava-se de todas as jovens da sua idade. ${ }^{50}$

Seu caráter e a sua conduta eram assim: respeitável em tudo, falava pouco, obedecia com prontidão, era cordial e muito modesta com os homens, séria e sossegada, fervorosa na oração, reverente, educada e respeitosa com as pessoas, a tal ponto que todos admiravam sua inteligência e a suas palavras (...) Sem nenhum orgulho, oposta à suntuosidade e à moleza. Possuía uma extraordinária humildade. ${ }^{51}$

No entanto, tal perfil monástico de Maria está misturado com elementos patriarcais. E isso contribuiu para moldar, no correr dos séculos, a imagem de Maria como mulher submissa, silenciosa e silenciada. Nosso monge caracteriza os traços físicos de Maria, baseado provavelmente no modelo utilizado nos ícones da época.

Maria era de estatura mediana, mas alguns disseram que era mais alta. Tinha a pele cor de trigo, de cabelos ruivos, olhos claros e um olhar suave, com sobrancelhas escuras, nariz fino e proporcionado. As mãos e os dedos também eram finos, com o rosto retangular, cheia de doçura e de graça divina. $^{52}$

Ora, tal "design" se compagina parcialmente com o das mulheres da Galileia do tempo de Jesus. Pois a jovem de Nazaré provavelmente apresentava o perfil característico de mulheres de tez morena. Mas o autor parece ignorar que ela teria mãos calejadas, típicas de quem executa tarefas da casa, carrega potes de água e de alimentos, cuida dos animais domésticos, ajuda no plantio e na colheita.

Além das características de conduta, Epifânio enfatiza o espírito de trabalho (laboriosidade), uma qualidade fundamental da vida monástica, ao lado da oração. Conjugando tudo isso, desde cedo Maria é exemplo de vida. E assim se torna uma liderança entre as mulheres.

Maria fiava lã, destinada ao templo do Senhor. (Com tal trabalho) ela se sustentava. Era constante nas orações, na leitura, no jejum, no trabalho

\footnotetext{
${ }^{50} \mathrm{VM} 5$.

${ }^{51} \mathrm{VM} 6$.

${ }^{52} \mathrm{VM} 6$.
} 
manual e em todas as virtudes. De modo que Maria, realmente santa, tornou-se a mestra de muitas mulheres, por seu estado de vida e a variedade de seus trabalhos (manuais). ${ }^{53}$

Mesmo depois de assumida como esposa de José, Maria cultiva as peculiaridades de monges e monjas: "ordenada e santa nas palavras, costumes e atividades" ${ }^{54}$ Algumas dessas qualidades também compõe o perfil de Madalena. Essa é descrita como uma mulher ativa, que tocada pelas palavras e os gestos de Jesus, renunciou a todos os seus bens, aderiu a Cristo e o seguiu, na companhia de Maria. ${ }^{55}$

No entanto, Epifânio cai no exagero, ao descrever as atitudes de Maria na comunidade primitiva, após a ressurreição e ascensão de Jesus. A Theotókos é descrita como asceta e milagreira.

(Maria) intensificou a prática das asceses e as genuflexões (..) Até hoje se mostram as cavidades de seus joelhos nos mármores da Santa Sião. E sobre a pedra, o lugar onde ela se reclinava e descansava um pouco do sono natural. Todas as pessoas lhe prestavam grande respeito e veneração (..) Atendendo aos enfermos, curava a muitos; libertava os endemoninhados dos maus espíritos imundos. Dava esmolas e cuidava dos pobres e das viúvas. Enquanto vivia, nenhum dos doze apóstolos foi enviado, nem se afastou dela. ${ }^{56}$

Essas expressões maximalistas destoam com a grande parte da narração de Epifânio. Provavelmente, se deixou influenciar pelos Apócrifos do Trânsito da Theótokos.

Uma questão problemática diz respeito à visão de Epifânio a respeito da castidade e da sexualidade. Segundo ele, pelo fato de ser pura e santa, Maria não teve nenhum desejo sexual. Na expressão do autor, "não conhece a concupiscência da carne". Pois tal desejo era identificado como manifestação do Pecado. E para complicar ainda mais as coisas, nosso monge associa a "pureza sexual" com a virgindade no parto.

Ela, efetivamente, não possuía a virgindade e a continência com luta, como as demais mulheres mais modestas e cuidadosas da decência. E sim,

\footnotetext{
${ }^{53} \mathrm{VM} 6$.

${ }^{54} \mathrm{VM} 11$

${ }^{55} \mathrm{VM} 19$.

${ }^{56} \mathrm{VM} 22$.
} 
tinham-na por natureza, o que é uma coisa extraordinária em relação a todas as mulheres, e alheia à natureza humana. Isto é o que havia dito o profeta Ezequiel: "A porta oriental ficara fechada e ninguém passará por ela, a não ser o Senhor Deus de Israel. Só Ele entrará e sairá por ela. Será porta fechada" (Ez 44,2-3) (..) Todos os Profetas e Apóstolos concordam neste ponto (..) como o grande Dionísio Areopagita: "o parto sem dor também atesta a concepção virginal". Atanásio de Alexandria e Leão de Roma disseram que ela desconheceu a concupiscência de varão e todos os sínodos afirmam o mesmo. ${ }^{57}$

Convém recordar que tal visão pessimista com relação à sexualidade humana, relacionando-a com o pecado, se manifesta em muitos escritos patrísticos, e merece uma reflexão à parte. Tomemos, por exemplo, a clássica obra de Gregório de Nissa, "Tratado sobre a Virgindade", escrita aproximadamente no ano $371 .^{58}$ Segundo o autor, vários vícios, paixões humanas e pecados se manifestam em quem escolhe a vida conjugal. ${ }^{59}$ Ceder à paixão da carne, ou da cobiça, ou da vanglória, a longo prazo leva a submetermo-nos às outras. ${ }^{60} \mathrm{~A}$ opção pela virgindade, por sua vez, "é uma arte e uma força de vida mais divina", que ensina a nos fazer "semelhantes à natureza não corpórea", dos anjos. ${ }^{61}$ Tal visão da prioridade do celibato leva Jerônimo a negar a hipótese de que José era viúvo. Ou seja, teria passado por uma vida conjugal, antes de encontrar Maria. Jerônimo sustenta que "José foi virgem por Maria, de tal modo que de umas núpcias virginais nasceu um Filho virgem". ${ }^{62}$

O livrinho de Epifânio testemunha a estreita relação entre o desenvolvimento da vida consagrada nos primeiros séculos e o crescimento da espiritualidade mariana. De um lado, o perfil de Maria é realçado conforme os valores do estado de vida monacal. De outro lado, ela constitui o exemplo paradigmático dos discípulos e discípulas de Jesus, em qualquer estado de vida.

\footnotetext{
${ }^{57} \mathrm{VM} 10$.

${ }^{58}$ GREGORIO DE NISSA, La virginidad.

${ }^{59}$ GREGORIO DE NISSA, La virginidad, IV, 1-3.

${ }^{60}$ GREGORIO DE NISSA, La virginidad, IV, 5-6.

${ }^{61}$ GREGORIO DE NISSA, La virginidad, IV, 8.

${ }^{62}$ JERÓNIMO, La perpetua virginidad de María, 19.
} 


\section{Maria, a sempre Virgem}

\subsection{Virgem antes e no parto}

Como já vimos, Epifânio assume parcialmente as narrativas sobre Maria, que recebeu de outras fontes, sobretudo os apócrifos. Então, segundo ele, Maria de Nazaré foi entregue por Joaquim e Ana como consagrada no templo de Jerusalém, com a idade de sete anos. ${ }^{63}$ Quando tinha doze anos de idade, estava rezando às portas do Santuário. Então, à meia noite, uma luz resplandeceu mais que o brilho do sol e uma voz disse: "Tu serás a mãe do meu Filho". ${ }^{44}$ Aos quatorze anos, "quando se manifesta a fraqueza da natureza das mulheres", ${ }^{65}$ os sacerdotes escolhem o viúvo e velho José, que tinha aproximadamente setenta anos, para cuidar dela. Maria viveu na casa de José, com os seus seis filhos, durante seis meses. Então sucedeu a anunciação. Ninguém soube o que tinha acontecido, e ela guardou segredo, até a exaltação de Jesus. "Segundo o costume, permaneceu rezando, em jejuns. E pela hora nona do dia apareceulhe o arcanjo Gabriel, enviado de Deus, e manifestou-lhe todos os mistérios do Unigênito Filho de Deus, que estão escritos nos Evangelhos". ${ }^{66}$

Maria não contou nada para José. Apenas revelou para Isabel as palavras do anjo, durante a visitação. E "as duas guardaram dentro de si o mesmo mistério". ${ }^{67}$

Epifânio suprime as fantasiosas narrativas dos apócrifos a respeito da "dúvida de José". Simplesmente diz: "e como, com o passar do tempo, se avolumasse seu ventre, José, considerando-a santa, mas ignorando os mistérios ao seu respeito, dominado pelo pudor, quis afastá-la ocultamente de sua casa. Mas o anjo de Deus o impediu, segundo disse o evangelista Mateus". ${ }^{68}$

No que diz respeito à virgindade no parto, Epifânio "filtra" vários elementos mágicos dos apócrifos. Por exemplo, não descreve a cena absurda da virgindade no parto, do Protoevangelho de Tiago. Segundo tal apócrifo, quando Maria estava para dar à luz, José encontra uma caverna, leva-a para dentro e, deixando seus filhos com ela, busca uma parteira na região de

\footnotetext{
${ }^{63} \mathrm{VM} 4$.

${ }^{64} \mathrm{VM} 6$.

${ }^{65} \mathrm{VM} 7$.

${ }^{66} \mathrm{VM} 9$.

${ }^{67} \mathrm{VM} 11$.

${ }^{68} \mathrm{VM} 11$.
} 
Belém. ${ }^{69}$ Enquanto caminha, percebe que o tempo havia parado. As pessoas permaneciam imóveis. Chama então a parteira. Essa entra na gruta, que estava repleta de luz e de fumaça. Então, eles encontram Maria amamentando a criança. $\mathrm{O}$ texto gnóstico deixa claro, pela narrativa, que Jesus não havia nascido de maneira normal. A parteira se surpreende ao ver tal milagre. Seguese uma cena esdrúxula.

Ao sair a parteira da gruta, veio ao seu encontro Salomé.

— Salomé, Salomé! - exclamou. — Tenho de te contar uma maravilha nunca vista. Uma virgem deu à luz; coisa que, como sabes, não permite a natureza humana.

Salomé replicou:

- Pelo Senhor, meus Deus, não acreditarei em tal coisa, se não me for dado tocar com os dedos e examinar sua natureza.

Havendo entrado a parteira, disse a Maria:

- Prepara-te, porque há entre nós uma grande querela em relação a ti.

Salomé, pois, introduziu o dedo em sua natureza, mas, de repente, deu um grito, dizendo:

—Ai de mim! Minha maldade e minha incredulidade é que têm a culpa! Por descrer do Deus vivo, desprende-se de meu corpo minha mão carbonizada. Dobrou os joelhos diante do Senhor (...) Apareceu um anjo do céu, dizendo-lhe:

- Salomé, Salomé, Deus escutou-te. Aproxima tua mão do menino, toma-o e haverá para ti alegria e prazer. Acercou-se Salomé e o tomou (...) De repente, sentiu-se curada e saiu em paz da gruta. ${ }^{70}$

Epifânio é discreto e respeitoso. Apenas se refere ao apócrifo de Jacob, $o$ hebreu (Protoevangelho de Tiago): "como o parto fora singular e extraordinário em tudo, apalpada por uma obstetra, Maria se encontrou virgem como antes do parto". ${ }^{71}$

\subsection{A opção celibatária por toda a vida}

A elaboração literária de Epifânio compartilha a crença na virgindade perpétua de Maria. Como já vimos, ele narra que Maria foi deixada no

\footnotetext{
${ }^{69}$ PET 18.

${ }^{70}$ PET 19 e 20.

${ }^{71} \mathrm{VM} 10$.
} 
templo, como consagrada, aos 7 anos de idade. Na difícil condição de mulher órfã, trabalha duramente para garantir seu sustento, tecendo com vários tipos de fios. E sem deixar de estudar. ${ }^{72}$ Como convém a monges e monjas ideais!

E José, o carpinteiro e primo de Maria? Ele havia se casado com uma tal Salomé, com a qual gerou prodigiosa descendência. "E tiveram sete filhos: Tiago, Simão, Judas, José, Sobe, Marta e Maria. Salomé, esposa de José, morreu. Ele viveu na viuvez e em continência, com setenta anos aproximadamente. Era pobre de bens e humilde carpinteiro como oficio. Habitava em Nazaré, povoado da Galiléia". ${ }^{73}$

Com isso, o autor concilia a crença na virgindade perpétua de Maria com os problemáticos textos bíblicos sobre os "irmãos e irmãs" de Jesus. Esses seriam filhos do primeiro casamento de José. Interessante notar que esta interpretação encontra variantes em diferentes apócrifos. A "História de José, o carpinteiro" (HJC), não nomeia a primeira esposa do carpinteiro de Nazaré, e diverge quanto ao número e nome das filhas. "Este homem, José, se uniu em santo matrimônio a uma mulher que lhe deu filhos e filhas (...): Judas, Joset(o), Tiago e Simão; Lísia e Lídia". ${ }^{74}$

Ainda segundo esse apócrifo, quando Maria tinha 12 anos, foi encaminhada para a casa do velho e bom José. Maria viveu na casa de José, com os seus filhos, durante dois anos (!) até "o momento feliz", da concepção de Cristo. ${ }^{75}$ Logo que chegou lá, "ela encontrou o pequeno Tiago na condição de órfão e começou a dedicar-lhes afeição e cuidados. É este o motivo pelo qual foi chamada Maria, mãe de Tiago". ${ }^{76}$ É visível como o relato apócrifo deturpa o texto bíblico de Mc 15,40. Pois a Maria Mirófora, mãe de Tiago que foi ao sepulcro com outras duas mulheres, não é a mãe de Jesus.

Por que Maria, virgem consagrada no templo, será dada em casamento a José? Epifânio segue a versão criada pelo Protoevangelho de Tiago, porém subtrai o elemento gnóstico. Pois conforme o apócrifo, Maria deveria ser retirada do templo antes da primeira menstruação, para que o sangue não contaminasse o santuário. ${ }^{77}$

\footnotetext{
${ }^{72} \mathrm{VM} \mathrm{4,} 5$.

${ }^{73} \mathrm{VM} 7$.

${ }^{74}$ HJC II, 3.

${ }^{75} \mathrm{HJC}$ III, 6.

${ }^{76}$ HJC IV, 3.

${ }^{77}$ PET 8.
} 
Seguindo suas fontes, Epifânio conta que os sacerdotes promovem um "concurso" entre vários viúvos idosos, para escolher quem deveria zelar pela castidade da Virgem Maria. O que acontece então?

Zacarias, príncipe dos sacerdotes, o pai de João Batista, tomou doze galhos (..) e colocou-as ao redor do altar, dizendo: o Senhor manifestará, com algum sinal, a quem há de pertencer a Virgem. Enquanto eles rezavam, brotou o galho de José o carpinteiro. Então, pela disposição de Deus, deram-lhe Maria como esposa, não para relação matrimonial, e sim para proteção e preservação de sua íntegra virgindade. ${ }^{78}$

Epifânio repete o argumento que se tornou uma convicção de grandes figuras da patrística, como Jerônimo e Agostinho. ${ }^{79}$ Assim ele interpreta a pergunta de Maria ao anjo, em Lc 1,34: “como acontecerá isso, pois não conheço homem?" “(...) quer dizer: "nunca fui entregue em matrimônio a um homem para união conjugal, senão para ser guardada como virgem pura e intacta, pois esta foi a causa dos esponsais". ${ }^{80}$

Se Maria foi consagrada no templo, se não tinha "o desejo da carne", se permaneceu intacta no parto, daí se segue que manteve sua opção celibatária durante toda a vida. Para completar a narrativa, outros fatores coadjuvantes afloram da narrativa. José é um ancião de idade muito avançada (70 anos somente de viuvez!). E os irmãos de Jesus provém do primeiro casamento do carpinteiro de Nazaré.

\section{A dormição de Maria}

Epifânio dá muita importância ao evento da passagem de Maria para a Vida Eterna. Este era um dos pontos altos da piedade mariana no oriente, a partir do século VII. Ele faz algumas inferências, servindo-se de questionáveis fontes apócrifas. Por exemplo, diz que "quando Paulo foi arrebatado desde Éfeso, isto aconteceu por motivo da Dormição da Theotókos. A frase de Paulo: "Cristo apareceu, após da Ressurreição, a mais de quinhentos irmãos

\footnotetext{
${ }^{78}$ VM 8. Na versão do protoevangelho de Tiago, “ao pegar José o último galho, eis que uma pomba saiu dele e se pôs a voar sobre sua cabeça. Então o sacerdote disse: 'A ti coube a sorte de receber sob tua custódia a Virgem do Senhor'” (PROTO-EVANGELHO de Tiago, cap. 9).

${ }^{79}$ AGOSTINHO, A Virgem Maria, p. 28.29.33.75.

${ }^{80} \mathrm{VM} 8$.
} 
juntos" (1Cor 15,6), aludiria também ao evento ligado à Dormição. ${ }^{81}$ Mais. Até "as almas dos outros santos, que já haviam morrido antes, todas estiveram presentes". 82

Apesar deste caráter apoteótico, a narrativa sobre a dormição é despojada de vários elementos mágicos dos apócrifos. Veja-se, a título de comparação, o Trânsito de Maria, de Pseudo-Melitão de Sardes (PTM), recensão B1. ${ }^{83}$ Segundo esse escrito, dois anos depois da morte e ressurreição de Jesus, Maria começa a chorar no seu quarto, na casa de seus pais, situada no monte das Oliveiras.$^{84} \mathrm{Um}$ anjo the traz do paraíso um ramo de palmeira, como sinal da morte vindoura. Maria teme que a alma, ao sair do corpo, encontre o príncipe das trevas. Então, a palma se torna resplandecente de grande luz. ${ }^{85}$ A seguir, cada apóstolo, que estava disperso pelo mundo anunciando o Evangelho, é transportado numa nuvem e deixado diante da porta da casa de Maria, onde se reúne com seus companheiros, passando três dias em oração com ela. ${ }^{86}$

Então, Jesus desce do céu com grande multidão de anjos, que entoam hinos de louvor. Enquanto Jesus conversa com Maria, ela, dando graças a Deus, deita-se na cama e entrega o espírito. Os apóstolos veem que sua alma irradia tal claridade que supera a brancura da neve, da prata e todos os metais. ${ }^{87}$ Jesus entrega a alma de Maria aos anjos Miguel e Gabriel. Três virgens tomam o corpo de Maria para levá-lo ao funeral. Enquanto tiram sua roupa para lavar o corpo e revesti-lo com a veste fúnebre, seu corpo resplandece de luz e beleza. Espalha-se um agradável odor, de perfume incomparável. ${ }^{88}$

Os doze apóstolos carregam o esquife em procissão, cantando suavemente. À frente segue João, levando a palma. Então, acontece um novo milagre. Sobre o caixão aparece uma grande nuvem, e nela um exército de anjos que cantam suavemente. Tal espetáculo chama a atenção de uma multidão de quinze mil pessoas que vem presenciar o que está acontecendo e acompanha a procissão. ${ }^{89}$

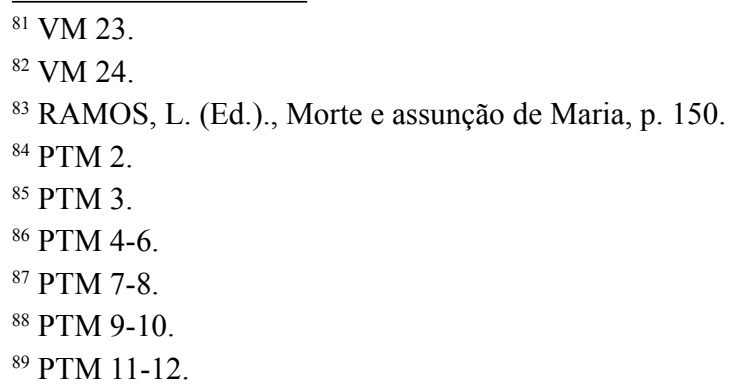


O chefe do sacerdote dos judeus, cheio de ira, tenta virar o esquife e atirar o corpo por terra. No mesmo instante, suas mãos ficam secas até o cotovelo e permanecem presas ao caixão. Então, ele se arrepende e suplica a Pedro que o cure. Pedro ouve seu apelo, mas pede que ele beije o caixão. Então, cessa toda dor e suas mãos ficam curadas. ${ }^{90} \mathrm{~A}$ seguir, com a palma são curados vários judeus castigados pela cegueira. ${ }^{91}$

Ainda segundo esse apócrifo, os apóstolos sepultam Maria no vale de Josafá, num sepulcro novo, e se sentam à porta do sepulcro. Aparece de novo Jesus, cheio de esplendor e rodeado de anjos. Pedro lhe pede: "ressuscita o corpo de Maria e conduze-a contigo ao céu, do mesmo modo que tu, vencida a morte, reinas na glória”. Jesus manda o arcanjo Miguel trazer a alma de Maria. Miguel gira a pedra da porta do sepulcro. Diz Jesus: "Sai, minha amiga! Tu, que não aceitaste a corrupção do relacionamento carnal, não sofrerás a dissolução do corpo no sepulcro". E ressuscita Maria do sepulcro. ${ }^{92}$ A seguir, Jesus beija Maria e retira-se, entregando sua alma aos anjos, para que a levem ao paraíso. Então, dá a paz aos apóstolos, eleva-se em uma nuvem e volta para o céu. Com Jesus, os anjos levam Maria ao paraíso de Deus. ${ }^{93}$

Agora, vejamos o capítulo dedicado ao tema da Dormição de Maria, na obra de Epifânio. Provavelmente, ele se serve de dois apócrifos assuncionistas: "Livro de São João, o teólogo" e "Livro de João, arcebispo de Tessalônica" ${ }^{94}$ Novamente, nosso monge não aceita grande parte das narrações fantasiosas. Mas talvez não tenha conseguido manter o mesmo equilíbrio, como aconteceu nos relatos da infância. Isso se deve ao fato de que a versão oriental da dormição a associa a uma vinda do Cristo Glorioso. E tal evento se reveste de grandeza incomparável! O céu desce à Terra, e com Cristo vem toda a corte dos anjos. Maria é uma figura singular nesta comunidade dos glorificados.

Epifânio enfatiza o caráter revelatório do evento. A partir do momento em que se desencadeia o processo da dormição, Maria revela todos os segredos de sua vida, que ainda não vieram à tona.

O anjo Gabriel veio à Santa Mãe de Deus quinze dias antes e anunciou

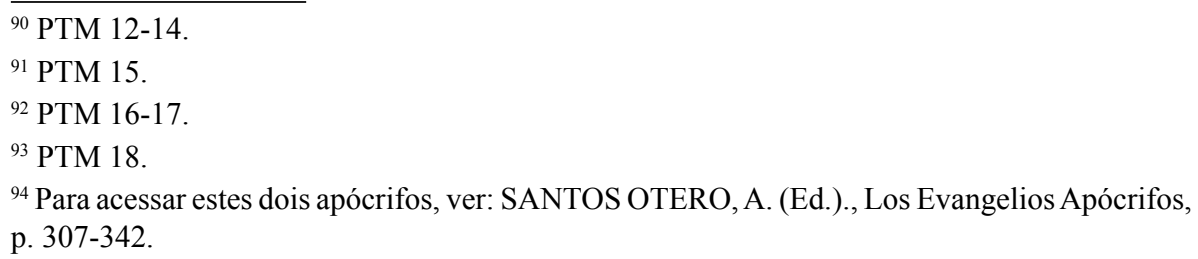


sua morte. E três dias antes veio o anjo Gabriel e deu-lhe a conhecer seu trânsito e a vinda do Senhor. Maria, enviando recado, convocou a todos os apóstolos. E muitas pessoas vieram junto Dela, de modo que se produziu um movimento grande e numeroso. Maria revelou-lhes os impressionantes mistérios que guardava em seu coração: a saudação do anjo, a aparição e a primeira manifestação que tivera, quando orava no Templo. Também fez testamento, com o afirma o apóstolo São Bartolomeu. Ela estava debilitada por causa das práticas ascéticas anteriores. ${ }^{95}$

Maria efetivamente morre. Depois, seu corpo se torna invisível. É uma forma discreta de afirmar que Maria ela assumida na Glória por seu Filho.

Quando chegou a sua hora, Cristo apareceu a todos. Por causa do resplendor de sua luz, todos se prostraram por terra, por medo, e ficaram como mortos. Ele lhes disse: a paz esteja convosco. E todos, pelo gozo, se recobraram. Enquanto, em princípio, os anjos cantaram hinos, os homens permaneciam calados. Logo depois, cantaram hinos. Ela, como num suave sono, aberta a boca, entregou o seu espírito ao seu Filho e seu Deus, com a idade de setenta e dois anos. Os anjos, cantando hinos novamente, foram embora. E os santos apóstolos cantaram seu próprio hino.

Depois de cantar os hinos, fazendo-lhe as exéquias, eles depositaram Maria no sepulcro de Getsêmani. Logo depois, observando isso todos os que estavam presentes, o corpo se fez invisível aos seus olhos. E cantando hinos de novo, foram embora cada um para sua casa. ${ }^{96}$

\section{Conclusão}

A título de conclusão, apresentaremos brevemente algumas reflexões, em forma de tópicos, sobre a contribuição deste escrito patrístico para a teologia e a pastoral, especialmente no que diz respeito a Maria.

(a) O texto de Epifânio, relativamente breve, atesta o fascínio da narração, que encanta os leitores de todos os tempos. Narrar fatos com intenção teológica tem um grande poder de transmitir as "verdades de fé", sem engessá-las. Tal recurso, tão comum em vários livros da Sagrada Escritura (desde o Êxodo e até os Evangelhos), permite dilatar o campo hermenêutico, estimulando

\footnotetext{
${ }^{95} \mathrm{VM} 25$.

${ }^{96} \mathrm{VM} 25$.
} 
novas descobertas. No dizer de Severino Croatto, ${ }^{97}$ propicia não somente a “exegese", mas também a "eisege". Traz à tona o sentido originário dos textos e amplia-os com perguntas da atualidade.

(b) A patrística nos ensina a trabalhar simultaneamente com várias formas de linguagem e canais comunicativos. Nos primeiros séculos se fazia teologia com narrações, homilias, hinos de louvor, profissão de fé dos concílios, disputas teológicas e representações pictográficas, sobretudo os ícones. É impressionante como a narração de Epifânio acerca da "Dormição de Maria" converge com os ícones deste tema: os personagens, os fatos narrados, a postura das pessoas. Eis um desafio teológico e pastoral para os dias de hoje: articular conceitos e analogias, narrações com descrição, rigor conceitual e leveza poética.

(c) O perfil da Mãe de Jesus em Epifânio converge em vários pontos fundamentais com a mariologia bíblica atual. No Evangelho de Lucas, Maria é esboçada como a primeira discípula e o modelo dos seguidores de Jesus. Ela ouve a Palavra, cultiva no coração e frutifica. Para Lucas, há uma prioridade do discipulado sobre a maternidade biológica (Lc 8,21; 11,27-28). Tal visão foi minoritária na Igreja até o Vaticano II. Há algumas exceções, como a bela afirmação de Santo Agostinho, de que Maria concebeu no coração antes de acolher o Verbo de Deus em seu ventre. E que somente esta acolhida na fé justifica sua maternidade. ${ }^{98}$

Então, Epifânio apresenta Maria não somente como a mãe de Jesus, mas também aquela que acompanha o Cristo e seus seguidores na vida pública. Epifânio realiza, com os limites de seu tempo, o mote proposto no capítulo 8 da Constituição Dogmática Lumen Gentium, do Concílio Vaticano II: compreender Maria dentro do mistério de Cristo e da Igreja. ${ }^{99}$ Utilizando a chave de leitura do Documento de Aparecida, diríamos: Maria é o modelo de vida para os discípulos e missionários de Cristo, e a mãe da comunidade, que nos acompanha. ${ }^{100}$

(d) Estranhamente, numa obra que pretende narrar o itinerário de Maria de Nazaré, estão ausentes vários relatos dos evangelhos, como: o Magnificat, a perda no templo e a vida em Nazaré. Há uma breve alusão a Caná, sem destacar a singular participação de Maria. Por qual motivo o autor não inclui

\footnotetext{
${ }^{97}$ CROATTO, J. S., Hermenéutica bíblica, p. 105-109.

${ }^{98}$ AGOSTINHO, Sermão, 25,7-8: PL 46,937-938 apud APRESENTAÇÃO de Nossa Senhora.

${ }^{99}$ LG 52-68.

${ }^{100}$ DAp 1, 270, 364, 553-554.
} 
estas cenas na "Vida de Maria"? Sustentamos aqui a hipótese que Epifânio não quis misturar sua narrativa com os textos dos Evangelhos, como fazem os apócrifos. Mantém assim a prioridade da Palavra de Deus. Isso pressupõe que as comunidades conheciam os textos bíblicos e faziam uso deles nas celebrações.

(e) Surpreendente é a forma como Epifânio, vivendo numa sociedade patriarcal, valoriza o protagonismo das mulheres. Faz questão de citar várias delas. Coloca Madalena no mesmo capítulo onde situa Pedro. Mostra a grande solidariedade entre a mulheres. Segundo nosso autor, as mulheres ajudam Maria em vários momentos, e também recebem seu apoio. Trata-se de uma bela lição de sororidade, que está em sintonia com a visão da teologia feminista atual. Maria, sendo uma figura singular, não se coloca acima das outras mulheres. E sim, com elas.

(f) Maria é descrita como uma mulher ativa e trabalhadora, inteligente e com desejo de aprender. Desenvolve várias habilidades. Aprende a ler. Não se abate, nem pelo fato de ser uma adolescente órfã. Em Maria, Epifânio mostra assim a dignidade e a força das mulheres.

No entanto, pode-se acusar o autor de reproduzir elementos da ideologia patriarcal com relação à mulher. Segundo Epifânio, Maria falava pouco, obedecia com prontidão, era modesta no trato com os homens, séria e sossegada. Além disso, a total ausência de desejo sexual, ${ }^{101}$ e não a integração das pulsões, seria um sinal de sua santidade.

(g) Ao comparamos a "Vida de Maria" com os apócrifos, percebemos notáveis diferenças. A mais marcante, do ponto de vista teológico, consiste em situar Maria em relação a Cristo e à comunidade de seus seguidores. Isso é fundamental, nesse momento histórico em que se proliferam devoções, hinos e textos exagerados, nos quais Maria praticamente ocupa o lugar de Jesus. Além disso, Epifânio filtra várias informações exageradas e mágicas, características dos apócrifos. No entanto, mantém o relato mitológico da dormição.

(h) Do ponto de vista da mariologia dogmática, constata-se que, no final do período patrístico já estava desenvolvida a crença em três dogmas marianos: Theotókos, Virgindade perpétua e Assunção. O dogma da Theotókos foi definido no Concílio de Éfeso. Já a virgindade perpétua não foi objeto de um concílio. A partir da narração dos apócrifos, consolidou-se como expressão de

${ }^{101} \mathrm{VM} 10$. 
fé da Igreja, sob o título de "sempre virgem Maria", incorporada ao credo. ${ }^{102}$ Já a assunção, dogma definido em 1950, apresenta versões distintas. No relato oriental, Maria morre de fato. Jesus busca sua alma. E posteriormente, seu corpo. Já a crença consolidada no ocidente nos últimos séculos foi resumida na afirmação de Pio XII na definição dogmática: "tendo terminado o percurso de sua vida terrena, Maria foi elevada de corpo e alma à glória do céu". ${ }^{103}$

Em síntese, constatamos que a "Vida de Maria", de Epifânio o Monge, é um relato precioso da patrística oriental, que traz significativas contribuições para a pastoral e a reflexão mariana no nosso tempo.

\section{Referências bibliográficas}

Agostinho. A Virgem Maria. Cem textos marianos com comentários. São Paulo: Paulus, 2017.

APRESENTAÇÃO de Nossa Senhora. Disponível em: <http://liturgiadashoras. org/oficiodasleituras/apresentacaoNS.html>. Acesso em: 20 de mai. 2018.

AS SANTAS Mirófiras de Jesus. Teologia Luterana. Disponível em: $<$ http:// teologiaeliturgialuterana.blogspot.com.br/2015/08/as-santas-miroforas-dejesus.html>. Acesso em: 20 de mai. 2018.

CELAM. V Conferência geral do episcopado latino-americano e do Caribe. Documento de Aparecida (2007). Disponível em: $<$ http://www.dhnet. org.br/direitos/cjp/a_pdf/cnbb_2007_documento_de_aparecida.pdf $>$. Acesso em: 20 mai. 2018.

\section{CONCÍLIO VATICANO II. Constituição Dogmática Lumen Gentium.}

Disponível em: $<$ http://www.vatican.va/archive/hist_councils/ii_vatican_council/ documents/vat-ii_const_19641121_lumen-gentium_po.html>. Acesso em: 20 mai. 2018.

CROATTO, J. S. Hermenéutica Bíblica. Um libro que enseña a leer creativamente la Bíblia. Buenos Aires: Lumen, 1994.

DAMASCENO. Homilías cristológicas y marianas. Introducción, tradución y notas de Guilherme Pons Pons. Madrid: Ciudad Nueva,1996.

DENZINGER, H. Compêndio dos símbolos, definições e declarações de fé

${ }^{102}$ Mais detalhes sobre a história deste dogma em: TEMPORELLI, C., Maria, mulher de Deus e dos pobres, p. 89-104.

${ }^{103} \mathrm{DH} 4175$. 
e moral. Traduzido com base na $40^{\mathrm{a}}$ edição alemã (2005), aos cuidados de Peter Hunermann. São Paulo: Paulinas / Loyola, 2007.

DOMINGO das santas miróforas. Disponível em: < https://ecclesia.org.br/ sinaxe/domingo-das-miroforas.html>. Acesso em: 04 agosto 2018.

EPIFANIO. Os últimos dias da Virgem Maria. Pais da Igreja. Disponível em: <https://www.ecclesia.com.br/biblioteca/pais_da_igreja/s_epifanio_os_ ultimos_dias_de_maria.html>. Acesso em: 20 de mai. 2018.

EPIFANIO. Introdução. In: EPIFANIO. Vida de María. Introducción, tradución y notas de Guilherme Pons Pons. 2.ed. Madrid: Ciudad Nueva, 1996. p. 5-12. (Biblioteca de Patrística, 8).5-12

EPIFANIO. Vida de María. Introducción, tradución y notas de Guilherme Pons Pons. 2.ed. Madrid: Ciudad Nueva, 1996. (Biblioteca de Patrística, 8).

EVANGELHO Armênio. In: SANTOS OTERO, A. (Ed.). Los Evangelios Apócrifos. Madrid: BAC, 2005. p. 185-191.

FREITAS FARIA, J. O outro Pedro e a outra Madalena segundo os apócrifos. Petrópolis: Vozes, 2004.

GHARIB, G. et al (Orgs). Testi mariani del Primo Millenio. Roma: Città Nuova, 1988. t.2 (Padri e altri autori bizantini).

GREGORIO DE NISSA. La virginidad. Introducción, tradución, notas e índices de Lucas F. Mateo-Seco. Madrid: Ciudad Nueva, 2000. (Biblioteca de Patrística, 49).

JERÓNIMO. La perpetua virginidad de Maria. Introduccíon, traducción y notas de Guilhermo Pons Pons. Madrid: Ciudad Nueva, 1994. (Biblioteca de Patrística, 25).

MORALDI, L. Evangelhos apócrifos. São Paulo: Paulus, 1999.

MURAD, A. Maria, toda de Deus e tão humana: compêndio de Mariologia. São Paulo: Paulinas; Aparecida: Santuário, 2016.

PROTO-EVANGELHO de Tiago. Disponível em: <http://www. universocatolico.com.br/index.php?/apocrifos-proto-evangelho-de-tiago. html>. Acesso em: 20 mai. 2018.

RAMOS, L. (Ed.). A história do nascimento de Maria. O proto-evangelho de Tiago (Papiro Bodmer). Petrópolis: Vozes, 1991. 
RAMOS, L. (Ed.). Morte e assunção de Maria. Livro do Trânsito do Pseudo Melitão de Sardes. Petrópolis: Vozes, 1991.

RAMOS, L. (Ed.). São José e o Menino Jesus. História de José, o carpinteiro. Evangelho do Pseudo Tomé. Petrópolis: Vozes, 1991.

SANTOS OTERO, A. (Ed.). Los Evangelios Apócrifos. Madrid: BAC, 2005. TEMPORELLI, C. Maria, mulher de Deus e dos pobres. Releitura dos dogmas marianos. São Paulo: Paulus, 2010.

Afonso Tadeu Murad

Doutor em Teologia pela Pontificia Universitá Gregoriana Docente do Departamento de Teologia da Faculdade Jesuíta de Filosofia e Teologia Belo Horizonte / MG - Brasil E-mail: amurad@marista.edu.br

Recebido em: 24/05/18 Aprovado em: 08/11/18 